these groups. Although their mean scores differ, the trend in $\mathrm{S}$ response is similar. It might be that the form of the distractions and their number are the same for these groups and not the same for the college group. Younger students might be more easily distracted qualitatively, as well as quantitatively, than older ones.

\section{REFERENCES}

DALRYMPLE-ALFORD, E. C. Interlingua interference in a color-naming task. Psychonomic Science, 1968, 10, 215-216.

DALRYMPLE-ALFORD, E. C., \& BUDAYR, B. Examination of some aspects of the Stroop color-word test. Perceptual \& Motor Skills, 1966, 23, 1211-1214.
KLEIN, G. S. Semantic power measured through the interference of words with color-naming. American Journal of Psychology, 1964, 71 576-588.

RAND, G., WAPNER, S., WERNER, M., \& MacFARLAND, J. H. Differences in performance on the Stroop color-word test. Journal of Personality, 1963, 31, 534-558.

SCHILLER, P. H. Developmental study of color-word interference. Journal of Experimental Psychology, 1966, 72, 105-108.

STEIN, K. B., \& LANGER, J. The relationship of covert cognitive interference in the color-phonetic symbol test to personality characteristics and adjustment. Journal of Personality, 1966, 34, 241-251.

STROOP, J. R. Studies of interference in serial verbal reactions. Journal of Experimental Psychology, 1935, 18, 643-662.

\title{
Semantic factors in conservation of weight'
}

SUSAN G. NUMMEDAL and FRANK B. MURRAY, University of Minnesota, Minneapolis, Minn. 55455

The performance of first- and second-grade $S$ s was analyzed on eight connotative-denotative discrimination problems and seven conservation-of-weight problems, each of which represented physical dimensions that are highly correlated on the semantic differential potency factor. The results indicated that $S s$ who made correct denotative discriminations performed significantly better on the conservation of weight problems than $S$ s who were unable to discriminate connotative from denotative meaning. The ability to make correct denotative discriminations is acquired prior to weight conservation and is perhaps a necessary, but not sufficient, condition for conservation of weight.

When a first grader is asked to report what differences exist between two objects that differ only in size, he may say that the larger of the two objects is not only larger, but that it is actually heavier and stronger than the smaller object even when he has contrary evidence about the weight and strength of the two objects (Ervin-Tripp \& Foster, 1960). The child apparently accepts the fact that "larger," for example, connotes "heavy" and "strong" as indicating that "larger" denotes "heavy" and "strong" as well. Of course, it is not unreasonable that the child should confuse connotative and denotative meaning in this instance, since more often than not size, weight, and strength are positively correlated in the child's experience.
In addition to failing to discriminate connotative and denotative meaning, the young child also fails to conserve or maintain the constancy of, for example, an object's weight when the object's shape, texture, or temperature is changed (Murray \& Johnson, 1968).

The present investigation explored the relation between these two kinds of children's failures, namely, the failure to discriminate connotative and denotative meaning, and the failure to conserve weight, by analyzing first and second graders' performance on eight connotativedenotative discrimination problems and seven conservation of weight problems, all of which were based on physical dimensions that were highly loaded on Osgood's semantic differential potency factor.

\section{SUBJECTS}

Subjects were 27 first graders ( 15 boys and 12 girls) with a mean age of 6.96 years (S.D. $=.57$ years), and 30 second graders (17 boys and 13 girls) with a mean age of 7.92 years (S.D. $=.44$ years).

\section{PROCEDURE}

The connotative-denotative discrimination test consisted of eight problems in which two objects differed in size (large-small), weight (heavy-light), texture (rough-smooth), shape (thick-thin, wide-narrow, or long-short), strength (strong-weak), or hardness (hard-soft). The physical dimensions of the stimulus pair for each problem were (1) size: a large block $\left(1 \frac{1}{2} \times 1 \frac{1}{2} \times 3 / 4\right.$ in.) and a small block $(3 / 4 \times 3 / 4 \times 1 / 2$ in.); (2) thickness: a thick block $\left(1 \frac{1}{4} \times 13 / 4 \times 1 / 2\right.$ in. $)$ and $a$ thin block $\left(1 \frac{1}{4} \times 13 / 4 \times 1 / 3 \mathrm{in}\right.$.);(3) width: a wide block $(13 / 4 \times 1 \times 3 / 4$ in.) and a narrow block $(13 / 4 \times 1 / 2 \times 3 / 4$ in.); (4) length: a long block
$(31 / 2 \times 3 / 4 \times 1 / 2$ in.) and a short block $(13 / 4 \times 3 / 4 \times 1 / 2$ in.); (5) weight: a heavy block ( $1 \mathrm{oz})$ and a light block $(1 / 2 \mathrm{oz})$ both $13 / 4 \times 3 / 4 \times 3 / 4$ in.; (6) texture: a rough block and a smooth block (both $13 / 4 \times 3 / 4 \times 3 / 4$ in.); (7) strength: a "strong" dry sponge and a "weak" damp sponge (both $11 / 2 \times 11 / 2 \times 1 / 2$ in.); (8) hardness: a hard ball of clay and a soft ball of clay (both $1 \frac{1}{2}$ in. diam). Ss, individually, were presented with a pair of these objects that differed on one dimension (e.g., size: one large and one small block) and were asked to say how the objects differed on that dimension. Ss, then, were asked if the objects differed on each of the other dimensions of thickness, width, length, weight, texture, strength, and hardness as well. For example, subjects were specifically asked, "Is one bigger and one smaller or are they both the same size?" and then, "Which one is bigger (or smaller)?" The same question form then was used to ask about the same objects for the following pairs of words: "wider, narrower; longer, shorter; thicker, thinner; heavier, lighter; rougher, smoother; stronger, weaker; harder, softer" in random order for each $S$.

In the seven conservation of weight problems, after each $\mathrm{S}$ agreed two clay balls were equal in weight, one of the two identical clay balls was transformed in size [(1) by adding a piece of clay], in shape [(2) by flattening it into a pancake, (3) by rolling it into a sausage, or (4) by pressing it into a wheel], in texture [(5) by roughing the surface with a table fork], or in strength [by having the $S$ imagine that the ball was (6) heated in the oven, or (7) frozen in a refrigerator] . After each transformation, Ss were asked, "Is one heavier and one lighter, or are they both the same weight?" and if Ss said the balls had different weights, they were asked, "Which one is heavier (or, one-half the time, lighter)?"

$$
\text { RESULTS }
$$

Subjects who made four or more correct conservation responses to the seven conservation of weight problems (one size, three shape, one texture, two strength problems) were scored as conservers, and Ss who made three or fewer correct responses were scored as nonconservers. There were, by this criterion, 9 conservers and 18 nonconservers in the first grade and 18 conservers and 12 nonconservers in the second grade. The difference in these proportions of conservers and nonconservers between the two grades was significant by a Fisher Test $(p=.0398)$.

A Cochran $Q$ analysis at each grade level of the difference between the proportion of conservers and nonconservers on each of the conservation problems showed significant differences between the proportions of conservers and nonconservers across the problems for both the first-grade Ss $(Q=76.54, p<.001)$ and the second grade 
Table 1

Number of Denotators and Connotators Who are Conservers and Nonconservers $(N=55)$

\begin{tabular}{lcc}
\hline & Conservers & Nonconservers \\
\hline Denotators & 24 & 18 \\
Connotators & 3 & 10 \\
\hline
\end{tabular}

Ss $(Q=66.07, p<.001)$. The percentage of conservation for all 57 Ss on each conservation problem was: temperature decrease, $19 \%$; temperature increase, $23 \%$; length, $42 \%$; thickness, $44 \%$; width, $56 \%$; roughness, $67 \%$; and $89 \%$ for an addition of substance.

Such a scale of difficulty of conservation of weight transformations implies that conservation of weight is a complex, situation- and transformation-specific concept. From the loadings of other adjective pairs on semantic differential scales on which "heavy" and "light" are loaded, one might easily discover other transformations (such as color, distance, etc.) which would elicit nonconservation responses.

On the connotative-denotative discrimination problems, each $\mathrm{S}$ made 56 responses, 7 on each of the eight problems. By the same one-half correct criterion used to determine conservation and nonconservation status, Ss making 28 or more correct discriminations were called, for want of a better word, "denotators" and those making 27 or fewer correct responses were classified as connotators. There were 18 denotators and 7 connotators in Grade 1 and 24 denotators and 6 connotators in Grade 2. (Two Ss in the first grade were eliminated from the analysis because they failed to make the initial discriminations of thickness and width required for the two problems in which pairs of stimuli actually differed on those dimensions.) Unlike conservation, the differences in these proportions of denotators and connotators between Grades 1 and 2 were not significant (.05 level) by the Fisher Test.

The relationship and the correlation between the ability to conserve weight under certain transformations and the ability to make appropriate connotative-denotative discriminations (Table 1) on the same physical dimensions on which the transformations were based was significant (Fisher Test exact probability: $\quad \mathrm{p}=.0322 ;$ Pearson product-moment correlation coefficient: $\mathrm{r}=.31, \mathrm{p}<.01$ ).

\section{DISCUSSION}

Of the $13 \mathrm{Ss}$ who failed to discriminate connotative and denotative meaning (Table 1), 3 were conservers and 10 were nonconservers, and of the 42 who discriminated connotative and denotative meaning, 24 were conservers and 18 were nonconservers. This finding suggests that the general ability to make denotative discriminations may be acquired prior to the ability to conserve weight and that perhaps it is a necessary condition for conservation of weight. But clearly, from the size of the frequencies in the nonconserver-denotator cell and the conserver-connotator cell, it is not a sufficient condition for conservation.

H. Sinclair-de Zwart (1969) examined the same relationship between children's language and conservation behavior. She compared children's performance in conservation of liquid tasks to their use of such differentiated terms as long, short, thick, and thin used to describe pencils that varied in length and thickness. She found that while $100 \%$ of the children who conserved used different terms for different dimensions, undifferentiated terms were used by approximately $75 \%$ of the nonconserving children, i.e., they used the same word to refer to two dimensions: e.g., fat for long and thick, or small for short and thin. Similar language-conservation relationships were found by Farnham-Diggory \& Bermon (1968).

The ability to use differentiated descriptive terms (Sinclair, 1969; Farnham-Diggory \& Bermon, 1968) or to distinguish connotative from denotative meaning, as this ability was investigated in the present study, probably only requires that children be able to judge what Piaget (1965) has called "gross quantity." Piaget has argued that correct judgments of gross quantity, while necessary, are not sufficient for the achievement of quantity conservation. The relationship between denotative discrimination and conservation found in this investigation is consistent with Piaget's notion that the development of gross or perceptual quantification culminates in quantity conservation.

To say that the ability to make connotative-denotative discriminations (or use differentiated terms) may be a necessary condition for conservation of weight in no way makes clear the role such a semantic ability plays in conservation acquisition. Sinclair (1969) has hypothesized that the training of the ability to use differentiated terms directs the attention of children to pertinent aspects of a problem, but, as Piaget insists, that in itself does not ipso facto bring about conservation and operational thought. Only further research and thought on the variables related to this language-thought relationship will establish the priority of either, and the character of the conservation phenomenon.

\section{REFERENCES}

ERVIN-TRIPP, S. M., \& FOSTER, G. The development of meaning in children's descriptive terms. Journal of Abnormal \& Social Psychology, 1960, 61, 271-275.

FARNHAM-DIGGORY, S., \& BERMON, M. Verbal compensation, cognitive synthesis and conservation. Merrill-Palmer Quarterly, 1968, 14, 215-228.

MURRAY, F. B., \& JOHNSON, P. E. A model for relevant and irrelevant transformations in children's concepts of weight. AERA Paper Abstracts, 1968 Annual Meeting, 308.

OSGOOD, C. E., SUCI, G. J., \& TANNENBAUM, P.H. The measurement of meaning. Urbana, IIl: University of Illin ois Press, 1957.

PIAGET, J. The child's conception of number. New York: W. W. Norton, 1965 (first published in French, 1941).

SINCLAIR-de ZWART, H. Developmental psycholinguistics. In D. Elkind and J. H. Flavell (Eds.), Studies in cognitive development: Essays in honor of Jean Piaget. New York: Oxford University Press, 1969.

\section{NOTE}

1. A shorter version of this paper was read at AERA Annual Meeting, Los Angeles, California, 1969. The research was supported by the Minnemast Project and the Center for Research in Human Learning at the University of Minnesota. The cooperation of Mrs. Genevieve Nelson, the faculty, and students of St. Anthony Park School, St. Paul, Minn., was greatly appreciated. 